\title{
Predictors of early and late stroke following cardiac surgery
}

\author{
Richard Whitlock MD, Jeff S. Healey MD, Stuart J. Connolly MD, Julie Wang MSc, Matthew R. Danter MD, \\ Jack V. Tu MD PhD, Richard Novick MD, Stephen Fremes MD, Kevin Teoh MD, Vikas Khera MD, \\ Salim Yusuf MD
}

\begin{abstract}
- Abstract
Background: Much is known about the shortterm risks of stroke following cardiac surgery. We examined the rate and predictors of longterm stroke in a cohort of patients who underwent cardiac surgery.

Methods: We obtained linked data for patients who underwent cardiac surgery in the province of Ontario between 1996 and 2006. We analyzed the incidence of stroke and death up to 2 years postoperatively.

Results: Of 108711 patients, 1.8\% (95\% confidence interval $[\mathrm{Cl}] 1.7 \%-1.9 \%)$ had a stroke perioperatively, and $3.6 \%(95 \% \mathrm{Cl} 3.5 \%-3.7 \%)$ had a stroke within the ensuing 2 years. The strongest predictors of both early and late stroke were advanced age ( $\geq 65$ year; adjusted hazard ratio $[\mathrm{HR}]$ for all stroke $1.9,95 \% \mathrm{Cl} 1.8$ 2.0), a history of stroke or transient ischemic attack (adjusted HR 2.1, 95\% Cl 1.9-2.3), peripheral vascular disease (adjusted HR 1.6, 95\% Cl 1.5-1.7), combined coronary bypass grafting

and valve surgery (adjusted $\mathrm{HR} 1.7,95 \% \mathrm{Cl} 1.5-$ 1.8) and valve surgery alone (adjusted HR 1.4, $95 \% \mathrm{Cl} 1.2-1.5)$. Preoperative need for dialysis (adjusted odds ratio [OR] 2.1, 95\% Cl 1.6-2.8) and new-onset postoperative atrial fibrillation (adjusted OR 1.5, 95\% Cl 1.3-1.6) were predictors of only early stroke. A CHADS 2 score of 2 or higher was associated with an increased risk of stroke or death compared with a score of 0 or 1 (19.9\% v. $9.3 \%$ among patients with a history of atrial fibrillation, $16.8 \%$ v. $7.8 \%$ among those with new-onset postoperative atrial fibrillation and $14.8 \%$ v. $5.8 \%$ among those without this condition).

Interpretation: Patients who had cardiac surgery were at highest risk of stroke in the early postoperative period and had continued risk over the ensuing 2 years, with similar risk factors over these periods. New-onset postoperative atrial fibrillation was a predictor of only early stroke. The $\mathrm{CHADS}_{2}$ score predicted stroke risk among patients with and without atrial fibrillation.
\end{abstract}

Competing Interests: None declared.

This article has been peer reviewed.

Correspondence to: Richard Whitlock, richard .whitlock@phri.ca

CMAJ 2014. DOI:10.1503 /cmaj.131214
0 troke remains a devastating complication following cardiac surgery, with substantial functional and economic impact. ${ }^{1-3}$ Stroke research in cardiac surgery has focused on the immediate postoperative period; ${ }^{4-9}$ however, most patients undergoing cardiac surgery have conditions such as hypertension, diabetes and atrial fibrillation, which place them at longterm risk of stroke.

Early and late outcomes among patients undergoing cardiac surgery could be improved if the risk of postoperative stroke was defined and predictors of stroke identified. With this information, clinicians could optimize medical therapy for stroke risk factors such as hypertension, ${ }^{10,11}$ improve the evidence-based use of oral anticoagulation in patients with atrial fibrillation and evaluate intraoperative surgical strategies (e.g., removal of the left atrial appendage ${ }^{12}$ ) in patients whose clinical characteristics predict an increased risk of stroke. We examined the rate and predictors of long-term stroke within 2 years after cardiac surgery.

\section{Methods}

\section{Study population}

We included all patients 18 years of age or older who underwent coronary artery bypass grafting (CABG), isolated valve surgery or combined $\mathrm{CABG}$ and valve surgery in the province of Ontario from Apr. 1, 1996, to Mar. 31, 2007.

\section{Databases}

We obtained patient data on deaths occurring outside of hospital from 3 administrative databases: the Cardiac Care Network of Ontario database, the Canadian Institute for Health Information Discharge Abstract Database and the Registered Persons Database. These databases have been used extensively to examine health outcomes because deidentified health care records can be analyzed using encrypted identifiers to track individuals over time. ${ }^{13-15}$ To deidentify the records, patient health numbers in the Cardiac Care Network and other Institute for Clinical Evaluative Sciences databases are 
encrypted into unique key numbers before the databases are linked together.

Available data on patient and surgery characteristics were captured prospectively from the Cardiac Care Network of Ontario database, an approach that has been validated. ${ }^{16}$ Data on history of atrial fibrillation and hypertension are not complete in this database; therefore, we determined the presence of these 2 conditions in the 10 years before surgery by searching the Discharge Abstract Database for records with corresponding International Classification of Diseases 9th revision (ICD-9) and 10th revision (ICD-10) codes (atrial fibrillation: ICD-9 code 4273, ICD10 codes I480 and I481; hypertension: ICD-9 codes 401-405, ICD-10 I10-I13 and I15). Patients with new-onset postoperative atrial fibrillation were defined as those who had no history of atrial fibrillation and whose hospital dis- charge record for the index admission had a diagnostic code for atrial fibrillation. Definitions for the other clinical variables can be found at the Cardiac Care Network Web site (www.ccn .on.ca/ccn_public/FormsHealthCareProvider/data _dictionary.aspx).

\section{Outcomes}

The primary outcome was stroke occurring within 2 years after surgery, either during the index hospital admission (early) or afterward (late). We identified patients with stroke by ICD-9 codes 430,431 and 434-436 and ICD-10 codes I60, I61, I63-I65 and G45 (excluding G454) in the Discharge Abstract Database. Secondary outcomes were perioperative stroke or death (occurring during the same index hospital admission) and late stroke or death (from the time of discharge from the index admission to 2 years after surgery).

Table 1: Baseline characteristics of 108711 patients who underwent cardiac surgery, by history of atrial fibrillation and by new-onset postoperative atrial fibrillation

\begin{tabular}{|c|c|c|c|c|}
\hline \multirow[b]{2}{*}{ Characteristic } & \multicolumn{2}{|c|}{$\begin{array}{c}\text { History of atrial fibrillation, } \\
\% \text { of patients* }\end{array}$} & \multicolumn{2}{|c|}{$\begin{array}{l}\text { New-onset postoperative } \\
\text { atrial fibrillation, } \\
\% \text { of patients* }\end{array}$} \\
\hline & $\begin{array}{c}\text { Yes } \\
n=9574\end{array}$ & $\begin{array}{c}\text { No } \\
n=99137\end{array}$ & $\begin{array}{c}\text { Yes } \\
n=18046\end{array}$ & $\begin{array}{c}\text { Not } \\
n=81091\end{array}$ \\
\hline \multicolumn{5}{|l|}{ Demographic } \\
\hline Age $\geq 65 \mathrm{yr}$ & 72.7 & 51.7 & 68.1 & 48.0 \\
\hline Female sex & 35.7 & 25.2 & 26.4 & 24.9 \\
\hline \multicolumn{5}{|l|}{ Risk factor } \\
\hline Congestive heart failure & 47.0 & 18.2 & 23.9 & 17.0 \\
\hline Creatinine level, $\mu \mathrm{mol} / \mathrm{L}$, mean $\pm \mathrm{SD}$ & $93.8 \pm 32.4$ & $91.7 \pm 25.4$ & $92.4 \pm 22.8$ & $91.5 \pm 25.9$ \\
\hline Stroke or transient ischemic attack & 7.4 & 3.6 & 4.6 & 3.4 \\
\hline Cerebrovascular disease & 16.9 & 10.3 & 12.5 & 9.7 \\
\hline Diabetes mellitus & 27.9 & 30.2 & 29.3 & 30.4 \\
\hline Dialysis & 1.8 & 1.1 & 1.0 & 1.1 \\
\hline Hypertension & 47.3 & 33.7 & 35.4 & 33.3 \\
\hline Left main coronary artery disease & 13.1 & 19.7 & 19.9 & 19.7 \\
\hline Previous myocardial infarction & 19.3 & 23.0 & 22.7 & 23.1 \\
\hline LV dysfunction (grade 2-4) & 51.8 & 49.6 & 48.3 & 49.9 \\
\hline Reoperation & 7.5 & 3.3 & 3.5 & 3.2 \\
\hline Peripheral vascular disease & 16.6 & 14.0 & 16.5 & 13.5 \\
\hline $\mathrm{CHADS}_{2}$ score, mean $\pm \mathrm{SD}$ & $1.63 \pm 1.17$ & $1.03 \pm 1.02$ & $1.20 \pm 1.08$ & $0.99 \pm 1.01$ \\
\hline \multicolumn{5}{|l|}{ Type of cardiac surgery } \\
\hline CABG & 48.1 & 79.6 & 71.0 & 81.5 \\
\hline Valve & 31.8 & 11.2 & 14.8 & 10.4 \\
\hline CABG + valve & 20.1 & 9.2 & 14.2 & 8.1 \\
\hline $\begin{array}{l}\text { Note: } C A B G=\text { coronary artery bypass graft su } \\
\text { or transient ischemic attack, LV = left ventric } \\
* \text { *Unless stated otherwise. } \\
\text { tNo history of atrial fibrillation and no posto }\end{array}$ & $\begin{array}{l}\text { for congestive } h \\
\text { on. }\end{array}$ & re, hypertensio & $75 \mathrm{yr}$, diabetes $\mathrm{n}$ & and prior stroke \\
\hline
\end{tabular}




\section{Statistical analysis}

We compared the prevalence of plausible risk factors for stroke ${ }^{17,18}$ (a) among patients with and without a history of atrial fibrillation and (b) among patients with new-onset postoperative atrial fibrillation and those without new-onset postoperative atrial fibrillation and no history of the condition. Risk factors that were plausible and available for analysis included age, sex, diabetes mellitus, congestive heart failure, left ventricular systolic function, cerebrovascular disease, valve surgery, CABG surgery, creatinine level, dialysis, hypertension, prior transient ischemic attack or stroke, hyperlipidemia, peripheral vascular disease, reoperation, history of myocardial infarction, left main coronary artery disease, history of atrial fibrillation and new-onset postoperative atrial fibrillation. We also evaluated the $\mathrm{CHADS}_{2}$ score (an acronym for congestive heart failure, hypertension, age $>75 \mathrm{yr}$, diabetes mellitus, and prior stroke or transient ischemic attack) $)^{19}$ as a composite predictor of stroke, independent of rhythm.

Risk factors with a $p$ value of less than 0.2 in the univariable analysis were entered into the multivariable analysis with no further selection. A multivariable Cox model was used for the primary outcome as well as for late stroke. The precise timing of early stroke events that occurred during the index hospital admission was not available; on the basis of previous findings, ${ }^{9,17}$ we assumed that all of these events occurred in the first 48 hours after surgery. Logistic regression was used to analyze the outcome of early stroke.

\section{Ethics approval}

This study was approved by the Research Ethics Board, Sunnybrook Health Sciences Centre.

Table 2: Predictors of stroke within 2 years after cardiac surgery

\begin{tabular}{|c|c|c|c|c|c|c|}
\hline \multirow[b]{2}{*}{ Variable } & \multicolumn{2}{|c|}{ Early stroke* } & \multicolumn{2}{|c|}{ Late stroke $\dagger$} & \multicolumn{2}{|c|}{ All stroke } \\
\hline & $\begin{array}{l}\text { Unadjusted } \\
\text { OR }(95 \% \mathrm{Cl})\end{array}$ & $\begin{array}{c}\text { Adjusted } \\
\text { OR } \neq(95 \% \mathrm{Cl})\end{array}$ & $\begin{array}{l}\text { Unadjusted } \\
\text { HR }(95 \% \mathrm{CI})\end{array}$ & $\begin{array}{c}\text { Adjusted } \\
\text { HR } \neq(95 \% \mathrm{Cl})\end{array}$ & $\begin{array}{l}\text { Unadjusted } \\
\text { HR }(95 \% \mathrm{Cl})\end{array}$ & $\begin{array}{c}\text { Adjusted } \\
\text { HR‡ }(95 \% \mathrm{Cl})\end{array}$ \\
\hline Age $\geq 65$ v. $<65 y r$ & $2.6(2.4-2.9)$ & & $2.1(1.9-2.3)$ & & $2.3(2.1-2.5)$ & \\
\hline Female sex & & $1.8(1.5-2.2)$ & & $1.4(1.2-1.6)$ & & $1.6(1.4-1.8)$ \\
\hline Male sex & & $2.2(2.0-2.5)$ & & $2.0(1.7-2.2)$ & & $2.0(1.9-2.2)$ \\
\hline Age $\geq 65 \mathrm{yr}$ & & $1.1(1.0-1.2)$ & & $1.2(1.1-1.4)$ & & $1.2(1.1-1.2)$ \\
\hline Age $<65$ yr & & $1.4(1.1-1.7)$ & & $1.7(1.5-2.2)$ & & $1.5(1.3-1.7)$ \\
\hline $\begin{array}{l}\text { Previous stroke or transient } \\
\text { ischemic attack }\end{array}$ & $2.8(2.4-3.3)$ & $2.1(1.8-2.5)$ & $2.8(2.4-3.2)$ & $2.2(1.9-2.5)$ & $2.8(2.5-3.1)$ & $2.1(1.9-2.3)$ \\
\hline Dialysis & $2.6(2.0-3.4)$ & $2.1(1.6-2.8)$ & $1.6(1.1-2.2)$ & $1.3(0.9-1.8)$ & $2.1(1.7-2.6)$ & $1.7(1.4-2.2)$ \\
\hline $\begin{array}{l}\text { History of myocardial } \\
\text { infarction }\end{array}$ & $1.0(0.9-1.1)$ & $1.0(0.9-1.1)$ & $0.9(0.8-1.0)$ & $0.9(0.8-1.0)$ & $0.9(0.9-1.0)$ & $1.0(0.9-1.0)$ \\
\hline Congestive heart failure & $2.0(1.8-2.2)$ & $1.4(1.3-1.5)$ & $1.6(1.5-1.8)$ & $1.1(1.0-1.2)$ & $1.8(1.7-2.0)$ & $1.2(1.2-1.3)$ \\
\hline History of atrial fibrillation & $1.7(1.5-1.9)$ & $1.2(1.1-1.4)$ & $2.0(1.8-2.3)$ & $1.4(1.3-1.6)$ & $1.9(1.7-2.0)$ & $1.3(1.2-1.5)$ \\
\hline $\begin{array}{l}\text { Left main coronary artery } \\
\text { disease }\end{array}$ & $1.1(1.0-1.3)$ & $1.2(1.1-1.4)$ & $1.0(0.9-1.2)$ & $1.0(0.9-1.2)$ & $1.1(1.0-1.2)$ & $1.2(1.1-1.3)$ \\
\hline $\begin{array}{l}\text { LV dysfunction grade } 2-4 \\
\text { v. grade } 1\end{array}$ & $1.2(1.1-1.3)$ & $1.1(1.0-1.2)$ & $1.2(1.1-1.3)$ & $1.2(1.1-1.4)$ & $1.2(1.1-1.2)$ & $1.2(1.1-1.3)$ \\
\hline Reoperation & $1.5(1.3-1.9)$ & $1.2(1.0-1.5)$ & $1.1(0.9-1.4)$ & $1.0(0.9-1.1)$ & $1.4(1.2-1.6)$ & $1.1(0.9-1.2)$ \\
\hline $\begin{array}{l}\text { Postoperative atrial } \\
\text { fibrillation }\end{array}$ & $1.7(1.5-1.9)$ & $1.5(1.3-1.6)$ & $1.1(1.0-1.2)$ & $1.1(1.0-1.2)$ & $1.3(1.2-1.5)$ & $1.2(1.1-1.3)$ \\
\hline
\end{tabular}




\section{Results}

\section{Population characteristics}

A total of 108711 patients were identified; their baseline characteristics are shown in Table 1 according to history of atrial fibrillation and new-onset postoperative atrial fibrillation. Isolated CABG was performed in $76.8 \%$ of patients, isolated valve surgery in $13.0 \%$ and combined $\mathrm{CABG}$ and valve surgery in $10.2 \%$. The $9574(8.8 \%)$ patients with a history of atrial fibrillation were older, more likely to be female and more likely to have valve or repeat surgery than those without a history of atrial fibrillation (Table 1). Postoperative atrial fibrillation developed in $18046(18.2 \%)$ of those without a prior history of atrial fibrillation. These patients were older and more likely to have congestive heart failure, a history of stroke or transient ischemic attack, peripheral vascular disease and to have undergone valve surgery than those without postoperative atrial fibrillation.

\section{Incidence of stroke and death}

Of the 108711 patients, $1.8 \%$ (95\% confidence interval [CI] $1.7 \%-1.9 \%$ ) had a stroke perioperatively and $3.6 \%$ (95\% CI 3.5\%-3.7\%) had a late stroke. The corresponding rates of death were $2.8 \%$ (95\% CI $2.7 \%$ to $2.9 \%$ ) and $6.8 \%(95 \% \mathrm{CI}$ $6.6 \%-6.9 \%)$.

Table 3: Predictors of death or stroke within 2 years after cardiac surgery, by sex

\begin{tabular}{|lcc|}
\hline & \multicolumn{2}{c|}{ Adjusted $\mathrm{HR}^{*}(95 \% \mathrm{Cl})$} \\
\cline { 2 - 3 } Variable & Men & Women \\
\hline Age $\geq 65 \mathrm{v} .<65 \mathrm{yr}$ & $2.1(2.0-2.2)$ & $1.6(1.5-1.7)$ \\
\hline $\begin{array}{l}\text { Previous stroke or transient ischemic } \\
\text { attack }\end{array}$ & $1.6(1.5-1.8)$ & $1.4(1.2-1.6)$ \\
\hline Dialysis & $2.8(2.5-3.2)$ & $2.7(2.2-3.3)$ \\
\hline Peripheral vascular disease & $1.6(1.5-1.7)$ & $1.5(1.4-1.7)$ \\
\hline Creatinine $\geq 90$ v. $<90 \mu m o l / L$ & $1.1(1.0-1.1)$ & $1.1(1.1-1.2)$ \\
\hline History of myocardial infarction & $1.0(1.0-1.1)$ & $1.1(1.0-1.2)$ \\
\hline Congestive heart failure & $1.9(1.8-2.0)$ & $1.8(1.7-1.9)$ \\
\hline History of atrial fibrillation & $1.4(1.3-1.5)$ & $1.3(1.2-1.4)$ \\
\hline Left main coronary artery disease & $1.3(1.2-1.3)$ & $1.4(1.2-1.5)$ \\
\hline LV dysfunction grade 2-4 v. grade 1 & $1.3(1.2-1.4)$ & $1.2(1.2-1.3)$ \\
\hline Reoperation & $1.4(1.3-1.6)$ & $1.4(1.2-1.6)$ \\
\hline Postoperative atrial fibrillation & $1.1(1.0-1.1)$ & $1.0(0.9-1.1)$ \\
\hline CABG and valve surgery v. CABG alone & $1.7(1.6-1.9)$ & $1.9(1.7-2.1)$ \\
\hline Valve surgery v. CABG & $1.4(1.3-1.5)$ & $1.3(1.2-1.5)$ \\
\hline $\begin{array}{l}\text { Note: CABG = coronary artery bypass grafting, Cl = confidence interval, HR }=\text { hazard ratio, } \\
\text { LV left ventricular. }\end{array}$ *Adjusted for all other variables in the table. & & \\
\hline
\end{tabular}

\section{Predictors of stroke}

The unadjusted and adjusted odds ratios (ORs) and hazard ratios (HRs) for the predictors of stroke at any time from the index hospital admission to 2 years postoperatively are shown in Table 2 . The strongest predictor of stroke at any time was a history of stroke or transient ischemic attack (adjusted HR 2.1, 95\% CI 1.9-2.3) and advanced age ( $\geq 65 \mathrm{yr}$; adjusted HR $1.9,95 \%$ CI 1.8-2.0). A significant interaction was observed between age and sex, with age having a stronger impact on risk among male patients. Other predictors included dependence on dialysis, peripheral vascular disease and valve surgery.

The risk factors for early stroke and late stroke were similar, with a few exceptions. The strongest predictors of early stroke were advanced age (unadjusted OR 2.6, 95\% CI 2.4-2.9), history of transient ischemic attack or stroke (adjusted OR $2.1,95 \%$ CI 1.8-2.5), preoperative dependence on dialysis (adjusted OR 2.1, 95\% CI 1.6-2.8), peripheral vascular disease (adjusted OR 1.6, 95\% CI 1.4-1.8), new-onset postoperative atrial fibrillation (adjusted OR 1.5, 95\% CI 1.3-1.6), combined surgery (adjusted OR 1.7, 95\% CI 1.51.9), congestive heart failure (adjusted OR 1.4, 95\% CI 1.3-1.5) and valve surgery (adjusted OR $1.3,95 \%$ CI 1.1-1.5). For late stroke occurring up to 2 years postoperatively, several important predictors were shared with those of early stroke, including advanced age (unadjusted HR 2.1, 95\% CI 1.9-2.3), a history of stroke or transient ischemic attack (adjusted HR 2.2, 95\% CI 1.9-2.5), peripheral vascular disease (adjusted HR 1.6, 95\% CI 1.4-1.8), a history of atrial fibrillation (adjusted HR 1.4, 95\% CI 1.3-1.6), combined CABG and valve surgery (adjusted HR 1.5, 95\% CI 1.4-1.8) and valve surgery (adjusted HR 1.3, 95\% CI 1.1-1.5). New-onset postoperative atrial fibrillation and preoperative need for dialysis were not associated with later stroke. The same interaction between sex and age was observed for early and late stroke events. The variables of prior stroke or transient ischemic attack and cerebrovascular disease were found to be collinear, and thus cerebrovascular disease was dropped from the final model without altering the results.

Table 3 presents the independent predictors of stroke or death according to sex. The results for stroke or death are consistent with those for stroke alone, and the impact of advanced age was greater among men than among women.

\section{Impact of $\mathrm{CHADS}_{2}$ score and atrial fibrillation on stroke and death}

Figure 1 presents the rate of stroke up to 2 years after surgery, stratified by $\mathrm{CHADS}_{2}$ score. Figure 2 presents the rate of stroke or death. Table 4 
presents the rate of stroke or death at 2 years by $\mathrm{CHADS}_{2}$ score and the associated hazard ratio. The rate of stroke or death in the absence of any atrial fibrillation was 5.8\% among patients with a $\mathrm{CHADS}_{2}$ score of 0 or 1 , as compared with $14.8 \%$ among those with a higher score. In the group of patients who had a history of atrial fibrillation, the rate of stroke or death at 2 years was $9.3 \%$ among those with a $\mathrm{CHADS}_{2}$ score of 0 or 1 , as compared with $19.9 \%$ among those with a higher score. In the group of patients with new-onset postoperative atrial fibrillation, the rate of stroke or death at 2 years was $7.8 \%$ among those with a $\mathrm{CHADS}_{2}$ score of 0 or 1 , as compared with $16.8 \%$ among those with a higher score.

The data showed that an increasing $\mathrm{CHADS}_{2}$ score predicted an increased risk of stroke and of stroke or death among patients with atrial fibrillation (preoperative or new-onset postoperative) and among those without atrial fibrillation.

\section{Interpretation}

Our study had 3 key findings. First, patients who underwent cardiac surgery were at highest risk of stroke in the early postoperative period but were also at risk over the ensuing 2 years. Second, the risk factors predicting early and late stroke were similar except for new-onset postoperative atrial fibrillation and preoperative need for dialysis, which predicted only early stroke. Third, the $\mathrm{CHADS}_{2}$ score predicted the 2-year risk of stroke and of stroke or death among patients with and without atrial fibrillation.

We examined the longer-term risk of stroke and its predisposing characteristics over the first 2 postoperative years in a large cohort of patients undergoing cardiac surgery. The strongest predictors of perioperative stroke were similar to those of late stroke (advanced age, history of stroke or transient ischemic attack, peripheral vascular disease, combined CABG and valve surgery, and isolated valve surgery). The results extend the observations made by others who have described similar predictors in the risk of early stroke..$^{5-8,18,20}$ Bucerius and colleagues found that cerebrovascular disease, preoperative infection and high transfusion requirement were the strongest independent predictors of perioperative stroke. ${ }^{21}$ Roach and colleagues found proximal aortic atherosclerosis, history of neurologic disease, use of intra-aortic balloon pump and age to be strong predictors of early adverse cerebral outcomes. $^{7}$ Our study showed that risk factors for perioperative stroke continued to predict risk of stroke in the ensuing 2 years.

The finding that new-onset postoperative atrial fibrillation was an independent predictor of early stroke but not of late stroke suggests that patients with postoperative atrial fibrillation should be considered for a short course of anticoagulation. Postoperative atrial fibrillation as a predictor of stroke has been debated within the literature. Hogue and colleagues found that it had no impact on the postoperative rate of stroke unless it was accompanied by low cardiac output syndrome,

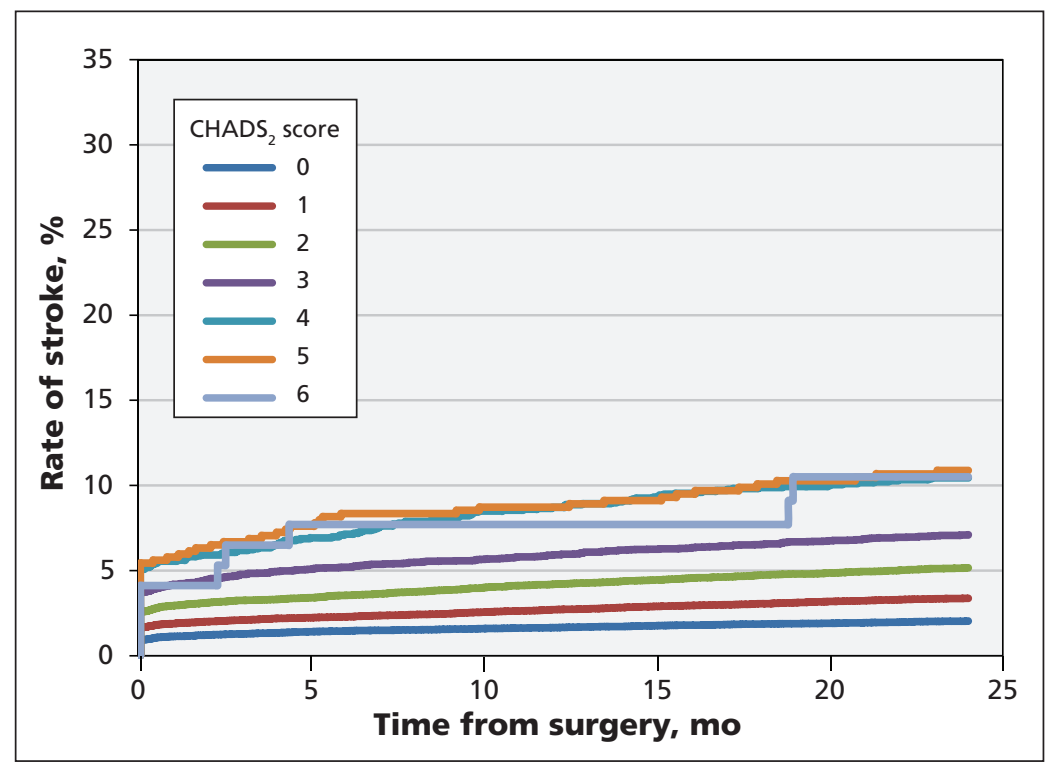

Figure 1: Rate of stroke from time of hospital admission for cardiac surgery to 2 years after surgery, by CHADS $_{2}$ score. CHADS $_{2}=$ acronym for congestive heart failure, hypertension, age $>75 \mathrm{yr}$, diabetes mellitus, and prior stroke or transient ischemic attack; 1 point is given for the presence of each of the first 4 conditions and 2 points for a history of stroke or transient ischemic attack. ${ }^{19}$

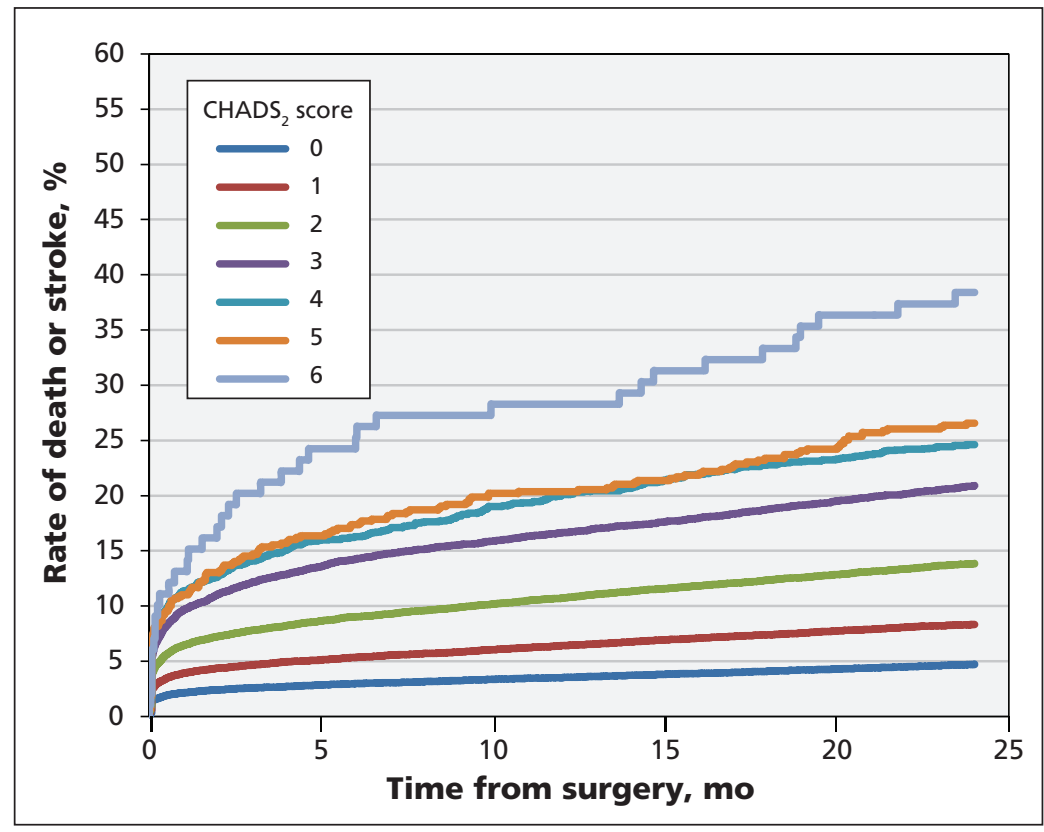

Figure 2: Rate of stroke or death from time of hospital admission for cardiac surgery to 2 years after surgery, by $\mathrm{CHADS}_{2}$ score. CHADS $\mathrm{C}_{2}=$ acronym for congestive heart failure, hypertension, age $>75 \mathrm{yr}$, diabetes mellitus, and prior stroke or transient ischemic attack; 1 point is given for the presence of each of the first 4 conditions and 2 points for a history of stroke or transient ischemic attack. ${ }^{19}$ 
with a resultant OR of 1.7 (95\% CI 1.0-2.9). ${ }^{6}$ Creswell and colleagues found that postoperative atrial fibrillation was associated with an increased incidence of stroke $(3.3 \%$ v. $1.4 \%$ without the condition, $p<0.0005) .{ }^{4}$ Most recently, Tarakji and colleagues found that postoperative atrial fibrillation was associated with a decreased rather than an increased risk of stroke. ${ }^{9}$ This association may have been the result of an aggressive anticoagulation strategy that is followed at the centre where the patients were recruited. Our study adds more than 100000 patients to this literature, with 18046 (18.2\%) who had postoperative atrial fibrillation, in whom there was a strong signal that this arrhythmia is associated with an increased risk of early stroke. Prospective studies are needed to define the use of antithrombotics in these patients.

The $\mathrm{CHADS}_{2}$ score is a validated clinical prediction rule for stroke risk in non-rheumatic atrial fibrillation ${ }^{22}$ and is used to guide antithrombotic therapy. Our findings showed that the $\mathrm{CHADS}_{2}$ score was an important predictor of stroke or death even in the absence of atrial fibrillation. This finding extends the results of Welles and colleagues, who showed that the score predicted ischemic stroke in the absence of atrial fibrillation. ${ }^{23}$ A prospective observational study involving cardiac surgery patients that closely tracks stroke subtypes, timing and therapies that may reduce the stroke risk is needed. Possible therapeutic approaches to be examined include optimization of antihypertensive therapy, optimization of antithrombotic therapy and intraoperative strategies such as occlusion of the left atrial appendage.

\section{Limitations}

This study has several limitations. First, the history of hypertension and atrial fibrillation were not validated within the Cardiac Care Network database. We used administrative claims data to identify rates of hypertension in a large population living in a single-payer health care system, an approach that has been validated previously. ${ }^{24}$ $\mathrm{Tu}$ and colleagues asserted that coding for atrial fibrillation would be very specific and thus rates would be accurately captured in this population. ${ }^{24}$ Our method of looking back 10 years for ICD codes for these diagnoses yielded prevalence rates that one would expect to see in this population. Nonetheless, Tu and colleagues conceded that relying on accurate coding of events such as atrial fibrillation by medical records personnel is a limitation of any study using administrative databases.

Second, intraoperative variables such as cardiopulmonary bypass time, cross-clamp time and on-pump versus off-pump procedures were not captured in the dataset. We were thus unable to interpret the influence of intraoperative variables on the rate of stroke.

Third, the dataset likely did not include all instances of postoperative atrial fibrillation. However, it probably did capture the instances that were clinically significant and prolonged.

Fourth, the dataset contained no information on postoperative anticoagulation use, either in hospital or on discharge.

Fifth, the timing of the postoperative stroke events that occurred in hospital was not available. The precise timing of stroke in relation to the onset of postoperative atrial fibrillation would better elucidate a causal relation. To further investigate this association, a prospective cohort study would be optimal.

Finally, information on losses to follow-up was not available. However, this would be limited to patients who left the province of Ontario, which would involve less than $1 \% .^{25}$

Table 4: Risk of stroke or death after cardiac surgery, by $\mathrm{CHADS}_{2}$ score*

\begin{tabular}{|c|c|c|c|c|c|}
\hline \multirow{2}{*}{$\begin{array}{l}\text { CHADS }_{2} \\
\text { score }\end{array}$} & \multirow{2}{*}{$\begin{array}{c}\text { No. of } \\
\text { patients }\end{array}$} & \multicolumn{2}{|c|}{$\%$ of patients $(95 \% \mathrm{Cl})$} & \multicolumn{2}{|c|}{ Unadjusted HR $(95 \% \mathrm{Cl})$} \\
\hline & & Stroke within $2 \mathrm{yr}$ & Stroke or death within $2 \mathrm{yr}$ & Stroke within $2 \mathrm{yr}$ & Stroke or death within $2 \mathrm{yr}$ \\
\hline 0 & 37492 & $2.0(1.9-2.2)$ & $4.7 \quad(4.5-4.9)$ & Reference & Reference \\
\hline 1 & 38751 & $3.3(3.1-3.5)$ & $8.3(8.1-8.6)$ & $1.7(1.5-1.8)$ & $1.8(1.7-1.9)$ \\
\hline 2 & 21938 & $5.0(4.7-5.3)$ & $13.8(13.4-14.3)$ & $2.6(2.3-2.8)$ & $3.1(2.9-3.3)$ \\
\hline 3 & 7761 & $6.7(6.2-7.3)$ & $20.9(20.0-21.8)$ & $3.6(3.2-4.0)$ & $4.8(4.5-5.2)$ \\
\hline 4 & 2071 & $9.8(8.5-11.1)$ & $24.6(22.8-26.5)$ & $5.3(4.5-6.2)$ & $5.8(5.3-6.4)$ \\
\hline 5 & 599 & $10.2(7.8-12.6)$ & $26.5(23.0-30.1)$ & $5.5(4.3-7.2)$ & $6.3(5.4-7.4)$ \\
\hline 6 & 99 & $9.1(3.3-14.9)$ & $38.4(28.6-48.1)$ & $5.2(2.7-10.0)$ & $9.6(7.0-13.3)$ \\
\hline
\end{tabular}

Note: $\mathrm{Cl}=$ confidence interval, $\mathrm{HR}=$ hazard ratio.

*Acronym for congestive heart failure, hypertension, age $>75 \mathrm{yr}$, diabetes mellitus, and prior stroke or transient ischemic attack; 1 point is given for the presence of each of the first 4 conditions and 2 points for a history of stroke or transient ischemic attack. 


\section{Conclusion}

Patients undergoing cardiac surgery were at increased risk of stroke, both perioperatively and in the ensuing 2 years. The predictors of stroke were similar for these 2 periods: advanced age, a history of stroke or transient ischemic attack, peripheral vascular disease, combined CABG and valve surgery, and isolated valve surgery. New-onset postoperative atrial fibrillation was a predictor of early but not late stroke. The role of early anticoagulation, particularly in the presence of an elevated $\mathrm{CHADS}_{2}$ score, should be explored in future research. A $\mathrm{CHADS}_{2}$ score of 2 or higher predicted an increased risk of stroke or death among patients with and without atrial fibrillation. Patients with an elevated score should be the focus for preventive strategies in future research irrespective of heart rhythm.

\section{References}

1. Daniel K, Wolfe CD, Busch MA, et al. What are the social consequences of stroke for working-aged adults? A systematic review. Stroke 2009;40:e431-40.

2. Demaerschalk BM, Hwang HM, Leung G. US cost burden of ischemic stroke: a systematic literature review. Am J Manag Care 2010;16:525-33.

3. Ringborg A, Yin DD, Martinell M, et al. The impact of acute myocardial infarction and stroke on health care costs in patients with type 2 diabetes in sweden. Eur J Cardiovasc Prev Rehabil 2009; 16:576-82.

4. Creswell LL, Schuessler RB, Rosenbloom M, et al. Hazards of postoperative atrial arrhythmias. Ann Thorac Surg 1993;56:539-49.

5. Gardner TJ, Horneffer PJ, Manolio TA, et al. Stroke following coronary artery bypass grafting: a ten-year study. Ann Thorac Surg 1985;40:574-81.

6. Hogue CW Jr, Murphy SF, Schechtman KB, et al. Risk factors for early or delayed stroke after cardiac surgery. Circulation 1999;100:642-7.

7. Roach GW, Kanchuger M, Mangano CM, et al. Adverse cerebral outcomes after coronary bypass surgery. Multicenter study of perioperative ischemia research group and the ischemia research and education foundation investigators. N Engl J Med 1996; 335:1857-63

8. Stamou SC, Hill PC, Dangas G, et al. Stroke after coronary artery bypass: incidence, predictors, and clinical outcome. Stroke 2001;32:1508-13.

9. Tarakji KG, Sabik JF III, Bhudia SK, et al. Temporal onset, risk factors, and outcomes associated with stroke after coronary artery bypass grafting. JAMA 2011;305:381-90.

10. Goldstein LB, Adams R, Alberts MJ, et al. Primary prevention of ischemic stroke: a guideline from the American Heart Association/American Stroke Association Stroke Council: cosponsored by the Atherosclerotic Peripheral Vascular Disease Interdisciplinary Working Group; Cardiovascular Nursing Council; Clinical Cardiology Council; Nutrition, Physical Activity, and Metabolism Council; and the Quality of Care and Outcomes Research Interdisciplinary Working Group: the American Academy of Neurology affirms the value of this guideline. Stroke 2006;37:1583-633.

11. Lawes CM, Bennett DA, Feigin VL, et al. Blood pressure and stroke: an overview of published reviews. Stroke 2004;35:1024.

12. Whitlock RP, Healey JS, Connolly SJ. Left atrial appendage occlusion does not eliminate the need for warfarin. Circulation 2009;120:1927-32; discussion 1932.

13. Guru V, Fremes SE, Austin PC, et al. Gender differences in outcomes after hospital discharge from coronary artery bypass grafting. Circulation 2006;113:507-16.

14. Hassan A, Newman A, Ko DT, et al. Increasing rates of angioplasty versus bypass surgery in Canada, 1994-2005. Am Heart J 2010; 160:958-65.
15. Silaruks S, Thinkhamrop B, Tantikosum W, et al. A prognostic model for predicting the disappearance of left atrial thrombi among candidates for percutaneous transvenous mitral commissurotomy. J Am Coll Cardiol 2002;39:886-91.

16. Lee DS, Stitt A, Wang X, et al. Administrative hospitalization database validation of cardiac procedure codes. Med Care 2013; 51:e22-6.

17. Salazar JDWR, Grega MA, Borowicz LM, et al. Stroke after cardiac surgery: short- and long-term outcomes. Ann Thorac Surg 2001;72:1195-201

18. Hogue CW Jr, Barzilai B, Pieper KS, et al. Sex differences in neurological outcomes and mortality after cardiac surgery: a society of thoracic surgery national database report. Circulation 2001; 103:2133-7.

19. Gage BF, van Walraven C, Pearce L, et al. Selecting patients with atrial fibrillation for anticoagulation: stroke risk stratification in patients taking aspirin. Circulation 2004;110:2287-92.

20. Puskas JD, Winston AD, Wright CE, et al. Stroke after coronary artery operation: incidence, correlates, outcome, and cost. Ann Thorac Surg 2000;69:1053-6.

21. Bucerius J, Gummert JF, Borger MA, et al. Stroke after cardiac surgery: a risk factor analysis of 16,184 consecutive adult patients. Ann Thorac Surg 2003;75:472-8.

22. Gage BF, Waterman AD, Shannon W, et al. Validation of clinical classification schemes for predicting stroke: results from the National Registry of Atrial Fibrillation. JAMA 2001;285: 2864-70.

23. Welles CC, Whooley M, Na B, et al. The $\mathrm{CHADS}_{2}$ score predicts stroke in the absence of atrial fibrillaion among subjects with coronary heart disease: data from the Heart and Soul Study. Am Heart J 2011;162:555-61.

24. Tu K, Campbell N, Chen ZL, et al. Accuracy of administrative databases in identifying patients with hypertension. Open Med 2007; 1:e18-26

25. Population 5 years and over by mobility status, by province and territory (New Brunswick, Quebec, Ontario) [table]. 2006 Census. Ottawa: Statistics Canada. Available: www.statcan.gc.ca/ tables-tableaux/sum-som/101/cst01/demo56b-eng.htm (modified 2007 Dec. 11; accessed 2014 July 16).

Affiliations: Population Health Research Institute and McMaster University (Whitlock, Healey, Connolly, Teoh, Khera, Yusuf), Hamilton, Ont.; Sunnybrook Schulich Heart Centre (Tu, Fremes), University of Toronto, Toronto, Ont.; Institute for Clinical Evaluative Sciences (Wang, Tu), Toronto, Ont.; Vanderbilt University (Danter), Nashville, Tenn.; London Health Sciences Centre (Novick), London, Ont.

Contributors: Richard Whitlock, Jeff Healey, Stuart Connolly and Vikas Khera contributed to the study concept and design. Richard Novick, Stephen Fremes, Kevin Teoh and Salim Yusuf contributed to the study design. Richard Whitlock, Julie Wang and Jack Tu were involved in statistical planning and analysis. Matthew Danter, Richard Novick, Stephen Fremes, Kevin Teoh and Salim Yusuf contributed to the interpretation of data. All of the authors critically revised the manuscript for important intellectual content and approved the final version submitted for publication.

Funding: The study was funded by a grant from the Canadian Network and Centre for Trials Internationally. Jack Tu is supported by a Tier 1 Canada Research Chair and a Career Investigator Award from the Heart and Stroke Foundation of Ontario. The study sponsors had no role in the design of the study, the collection, analysis or interpretation of the data, the writing of the report or the decision to submit the article for publication.

Disclaimer: The data used in this publication are from the Cardiac Care Network of Ontario and its member hospitals. The Cardiac Care Network of Ontario and the Institute for Clinical Evaluative Sciences (ICES) are funded by the Ontario Ministry of Health and Long-Term Care. The results and conclusions are those of the authors and should not be attributed to ICES or the ministry of health. 